\title{
PESONA KERATON SUMENEP DALAM DESAIN CINDERAMATA OLEH UKM KAYU UKIR KARDULUK, MADURA
}

\author{
Anggri Indraprasti'), Imam Santosa'), Prasetyo Adhitama ${ }^{3)}$ \\ ${ }^{1}$ Fakultas Seni Rupa Desain, ITB \\ anggri@student.itb.ac.id \\ ${ }^{2}$ Fakultas Seni Rupa Desain, ITB \\ imamz@fsrd.itb.ac.id \\ ${ }^{3}$ Fakultas Seni Rupa Desain, ITB \\ prasetyo@yahoo.com
}

\begin{abstract}
Sumenep is a town located at the east part of Madura Island, East Java Province. It has a distinctive history about the Keraton and its people. Build in 1762, the Keraton of Sumenep is the only cultural heritage building, existed in East Java which is categorized as a 'palace'. The people of Sumenep also inherit the skill of crafting wood, specifically in carving. The village of Karduluk is the only local craft industry in Madura which produce local wooden furniture with its Madurese and Keraton's flair. As a developing town with its rich cultural and historical background of the Keraton, Sumenep also needs to develop its wooden craft industry. This research studies the potential of the wooden craft industry of Karduluk in developing distinctive designs which can contribute to the region's tourism industry. One of the products that could contribute significantly is the local souvenir. May it be the official souvenir of the head of the Sumenep Region or the contemporary souvenir for the global tourism consumer. Using the ' $4 D$ design method' on developing products, define, design, develop and disseminate, this research uncover the hidden treasures of the Keraton's beauty from the wooden craft people of Karduluk.
\end{abstract}

Keywords: design, Keraton Sumenep, Karduluk, souvenir, wooden craft.

\section{PENDAHULUAN}

\subsection{Latar Belakang}

Globalisasi memberi peluang sekaligus tantangan untuk berbagai wilayah kabupaten di Indonesia pada sebuah kompetisi besar agar dapat mengembangkan potensi daerahnya masing-masing, mampu menarik investor dalam maupun luar negeri, menyiapkan SDM yang potensial, dan menarik wisatawan sebagai modal pengembangan daerah. Menurut Fadallah (2014) pemerintah kota diharapkan mampu merespon kondisi tersebut, antara lain dengan pembentukan citra yang dimiliki pada suatu tempat. Menurut Fadallah, (2014) persepsi pada kota dan citra yang dimilliki suatu tempat, menjadi komponen sukses atau gagalnya ekonomi, sehingga perlu dibangun persepsi dan citra suatu kota yang merepresentasikan identitas daerahnya dengan menciptakan brand yang dikenal dengan city branding. Salah satu variabel proses penerapan konsep city branding yaitu implementasi program promosi kota melalui berbagai media, relasi, dan kegiatan kreatif.

Sebagai kabupaten pewaris budaya keraton dan mulai menapakkan posisinya di skala internasional, Sumenep perlahan tapi pasti terus memperbaiki dan melengkapi sarana dan prasarana berskala internasional. Keberhasilan perbaikan sarana dan prasarana kabupaten serta peningkatan kualitas pelayanan pemerintah terhadap masyarakat sering mendapat apresiasi di kalangan pemerintah daerah dan pusat. Wujud keberhasilan pemerintah Kabupaten Sumenep dalam mengelola wilayahnya diantaranya adalah pada sektor tata wilayahnya, pelayanan masyarakat, administrasi pemerintahan dan ekonomi. Patut dipuji pemerintah Kabupaten Sumenep menjadi tuan rumah dari Festival Keraton Nusantara dan ASEAN bulan Oktober tahun 2018 lalu dan menjadi tujuan kunjungan para wisatawan dari dalam maupun luar negeri untuk belajar dan bertukar wawasan mengenai budaya Madura. Selain itu Kabupaten Sumenep juga menarik pebisnis untuk mengembangkan usaha di bidang wisata bahari.

Banyaknya kunjungan masyarakat dari berbagai kalangan ke Kabupaten Sumenep sangat berpengaruh pada sektor pariwisatanya. Berkaitan dengan hal tersebut pemerintah Kabupaten Sumenep harus mulai berbenah mengembangkan sektor pariwisatanya. Elemen penting dari sektor pariwisata 
tersebut diantaranya adalah cinderamata khas Kabupaten Sumenep. Cinderamata merupakan suatu media yang digunakan agar suatu kota/daerah tetap diingat dan bahkan memberikan nilai positif berupa rasa ikut memiliki oleh para wisatawan yang datang berkunjung. Selain itu nilai positif dari cinderamata adalah sebagai media mengenalkan kebudayaan dan historis suatu daerah/kota yang tertuang di dalamnya.

Suatu desain cinderamata memiliki syaratsyarat tertentu agar berhasil mencapai tujuannya sehingga perlu didesain secara cermat dan khusus. Sebaiknya cinderamata tidak hanya berfungsi sebagai benda hias, namun juga memiliki fungsi lain, sebagai media representasi budaya dari suatu tempat (kota, negara, daerah). Ekspresi estetika sangat erat kaitannya dengan nilai khas yang dikandung oleh cinderamata tersebut mengenai representasi sebuah tempat.

Jenis cinderamata beragam, dari yang dijual di kaki lima hingga cinderamata eksklusif untuk para tamu penting pemerintahan. Sepertihalnya kota-kota besar dunia, para pemimpin negara maupun pejabat wilayah kota memiliki cinderamata yang dirancang eksklusif untuk para tamunya. Pemerintah Kabupaten Sumenep sejak menjadi tuan rumah Festival Keraton Nusantara dan ASEAN mulai sering menerima tamu dari para pemimpin daerah bahkan perwakilan internasional, namun Kabupaten Sumenep belum siap dalam memberikan cinderamata yang representatif mewakili citra Kabupaten Sumenep dan dengan kualitas desain yang eksklusif. (berkelas internasional, bercitarasa internasional, dan berjiwa lokal).

Cinderamata eksklusif dirancang dengan cermat mempertimbangkan berbagai aspek rancangan seperti kualitas bahan, teknik, kemasan dan ekspresi estetika yang dikandung. Salah satu kerajinan lokal yang bahannya berkualitas dan dapat dikembangkan menjadi produk yang berkelas dan bercitarasa internasional adalah kayu ukir. Kayu ukir merupakan bahan yang memiliki karakter unik cenderung antik karena detail motif dan warnanya, bentuk serta finishing. Dari pengolahan bentuk, kayu ukir juga dapat memancarkan berbagai ekspresi benda, seperti anggun, riang, ceria maupun canda (lucu). Kayu ukir telah dikenal oleh masyarakat Indonesia sejak jaman Majapahit dan saat ini telah berkembang menjadi usaha kecil menengah (UKM) masyarakat.

Permasalahan saat ini, bupati sebagai kepala pemerintahan Kabupaten Sumenep yang sering menerima tamu penting dari berbagai kalangan dari dalam dan luar negeri belum memiliki cinderamata yang berkelas internasional, bercitrarasa internasional dan berjiwa lokal. Sehingga perlu dilakukan penelitian pengembangan cinderamata eksklusif berkelas dan bercitrarasa internasional yang berkarakter khas Sumenep untuk tamu Pemerintah Kabupaten Sumenep. Pengembangan cinderamata eksklusif difokuskan pada bahan kayu ukir karena memiliki karakter unik dan antik sekaligus dapat mengembangkan produk UKM kayu ukir Nusantara. Tujuannya agar melalui cinderamata khas Kabupaten Sumenep berbahan kayu ukir tersebut dapat meningkatkan citra Kabupaten Sumenep di mata para tamu dari dalam dan luar negeri. Selain itu penelitian ini bertujuan untuk mengembangkan produk kayu ukir Nusantara bekerjasama dengan perusahaan kayu ukir berkelas internasional.

\subsection{Perumusan dan Pembatasan Masalah}

UKM kayu ukir Kabupaten Sumenep saat ini hanya mendominasi pasar lokal dan belum ada yang berhasil menembus pasar internasional. Selain itu pengembangan jenis produknya belum diminati perusahaan berskala dunia. Pengembangan jenis produk kayu ukir yang berhasil adalah pada segmen pasar produk mebel lokal saja. Kendala perkembangan UKM kayu ukir di Kabupaten Sumenep diantaranya adalah masih kurangnya pengembangan ilmu pengetahuan dan regenerasi keterampilan kayu ukir ke masyarakat, khususnya melalui pendidikan formal di kalangan mahasiswa desain.

Berdasarkan kondisi tersebut rumusan masalah penelitian ini adalah bagaimana mengembangkan cinderamata aksesoris interior yang berkarakter khas Sumenep untuk para tamu Pemerintah Kabupaten Sumenep dari produk kayu ukir lokal menjadi produk yang mempunyai ekspresi modern dan berkelas internasional.

Dari rumusan masalah tersebut muncul pertanyaan penelitian sebagai berikut :

a. Bagaimana mengembangkan cindera-mata ekslusif yang berkarakter khas Sumenep dari bahan kayu ukir namun berkelas dan bercitarasa internasional?

b. Bagaimana mengembangkan aksesoris interior berbahan kayu ukir sebagai cinderamata untuk tamu Pemerintah Kabupaten Sumenep?

c. Bagaimana mengembangkan ilmu dan produk kayu ukir yang berkelas internasional melalui pendidikan formal khususnya di kalangan mahasiswa desain?

\subsection{Pembatasan Masalah}

a. Cinderamata berbahan kayu ukir sebagai aksesoris interior 
b. Pengenalan ilmu kayu ukir pada mahasiswa desain di Surabaya.

\subsection{Tujuan Penelitian}

a. Mengemas dinamika Sumenep dalam sebuah cinderamata berbahan kayu ukir, memiliki nilai estetis dan fungsional.

b. Mengenalkan Sumenep kepada tamu/ pimpinan daerah lain dalam wujud kayu ukir. Kayu ukir memiliki kekuatan kesan 'antik' dalam tampilannya sehingga diharapkan dapat menambah nilai lebih yang positif tentang citra Sumenep.

c. Pengenalan ilmu pengetahuan kayu ukir pada mahasiswa desain sehingga mahasiswa mengetahui SWOT kayu ukir untuk pengembangan material maupun desain kayu ukir sebagai elemen hias interior.

d. Ke depannya cinderamata aksesoris interior ini akan dikembangkan pada UKM lokal yang ada di sekitar Kabupaten Sumenep.

\subsection{Manfaat dan Target Penelitian}

a. Membangkitkan semangat cinta budaya, cinta lingkungan, dan perjuangan dalam membangun Kabupaten Sumenep agar sejajar dengan daerahdaerah setingkat lain di dunia.

b. Mengembangkan kualitas produk kayu ukir lokal yang berkelas internasional.

c. Mahasiswa mengetahui ilmu pembuatan kayu ulir dan pola kerja bengkel kayu ukir langsung dengan praktisi nasional maupun internasional.

d. Menambah variasi dan jenis produk kayu ukir lokal.

e. Menambah jenis produk cinderamata pemerintah Kabupaten Sumenep.

\section{KAJIAN LITERATUR (Hikayat Seni Ukir Madura)}

Terdapat berbagai versi mengenai hikayat ukir Madura dengan beberapa persamaan yaitu tokoh, masa Majapahit, dan cerita layang-layang. Dalam penelitian yang dilakukan oleh R.P. Angger Orie dan, hikayat ukir Madura menurut cerita rakyat versi Saleh Ruhmadi adalah sebagai berikut: terbatasnya data mengai tanggal dan waktu yang jelas di daerah Jawa Timur, terdapat sebuah kerajaan dimana hidup seorang penyungging (ahli melukis, mematung, dan mengukir) bernama Sungging Prabangkara, ahli seni.

Suatu hari Sungging Prabangkara diminta raja untuk membuat lukisan istri raja yang cantik. Tugas dilaksanakan dengan senang hati, namun ketika hendak melukis bagian dada, sang permaisuri tidak berkenan untuk membuka pakaian karena hanya raja yang berhak melihatnya. Oleh raja, Sungging Prabangkara diminta melukis dengan cara membayangkan saja dan dengan keahliannya, lukisan dapat dikerajakan dengan sangat bagus. Namun pada tahap akhir yaitu saat pengeringan lukisan, tanpa sepengetahuan Sungging Prabangkara, seekor lalat yang telah disihir jin jahat, hinggap di tinta hitam dan terbang hinggap di lukisan tepat di bagian dada sehingga "menodai" seluruh bagian tersebut. Ketika tiba saatnya raja melihat lukisan, raja marah besar karena melihat lukisan sang permaisuri yang menunjukkan bahwa Sungging Prabangkara telah melihat sendiri bagian yang dilarang oleh raja. Dengan rasa cemburu dan dendam, raja berniat membunuh Sungging Prabungkara.

Suatu pagi yang cerah raja menaikkan layanglayang dengan ukuran sangat besar. Layang-layang terbang tinggi karena kencangnya angin. Namun layang-layangpun terbang miring sehingga raja mengutus Sungging Prabangkara untuk naik dan membetulkan. Sungging Prabangkara yang sakti berhasil naik melalui tali layangan namun saat sudah di atas, raja memutus tali dan Sungging Prabankara terbawa layang-layang terbang tertiup angina melintas beberapa tempat. Saat melintas tersebut, alat-alat seni yang selalu dibawa oleh Sungging Prabangkara jatuh satu persatu. Konon alat-alat tersebut jatuh di Bali, Jepara, dan Madura.

Menurut R.P. Angger Orie dan Poerwadi, diduga para ahli, Sungging adalah salah satu pekerja dalam pembuatan candi-candi Hindu yang materialnya terbuat dari batu dan bata yang dapat diukir. Kemudian untuk mengembangkan keahliannya para Sungging mencoba memahat dan mengukir menggunakan material kayu. Bersamaan dengan meluasnya kerajaankerajaan Hindu, menyebar pula keahlian dan produk para Sungging. Gaya seni dan teknik tersebut dipengaruhi oleh masuknya budaya Islam, Cina, dan Barat. Salah satu bukti kuat gaya kesenian ukir peninggalan kebudayaan-kebudayaan tersebut adalah ukiran yang terdapat di masjid mantingan sebelah selatan Jepara dibuat ketika masa pemerintahan ratu Kalinyamat.

\section{METODE PENELITIAN}

Metode penelitian yang digunakan adalah sesuai kaidah ilmiah sebuah penelitian. Tahapan dirancang sesuai alur pengenalan kepada permasalahan hingga penarikan kesimpulan dari penelitian. Penelitian dilaksanakan selama 1 tahun. 
Sasaran penelitian untuk menghasilkan 10 prototipe cinderamata aksesoris interior yang berkarakter khas Sumenep untuk tamu Pemerintah Kabupaten Sumenep. Metode yang digunakan dalam penelitian ini adalah metode analisis dan pengembangan. Penelitian ini akan melalui empat tahap yakni tahap pendefinisian (define), perancangan (design), tahap pengembangan (develop), dan tahap penyebaran (disseminate). Untuk tahap pendefinisian, perancangan dan penyebaran dilakukan di Kabupaten Sumenep dan Kota Surabaya, sedangkan untuk proses pengembangan dilakukan di Sentra Kerajinan Kayu Ukir Karduluk, Sumenep.

\section{Tahap Pendefinisian (define)}

Tahap define merupakan tahap identifikasi obyek penelitian. Peneliti mengkaji data contoh cinderamata aksesoris interior berbahan kayu ukir yang sudah ada di pasaran. Data diperoleh dengan cara studi literatur, observasi dan wawancara yang kemudian dianalisa. Kemudian dari hasil analisa akan menentukan desain dan jenis produk yang tepat untuk menghasilkan cinderamata aksesoris interior berbahan kayu ukir yang berkarakter khas daerah Sumenep dan berkelas internasional.

a. Studi Literatur

Studi literatur tentang kayu ukir, branding kota, sejarah Kabupaten Sumenep, ikon dan karakter kabupaten, aksesoris interior berbahan kayu ukir, cinderamata.

b. Penggalian Data Ikon dan Karakter Khas Kabupaten Sumenep

Jenis data primer yang digali adalah data ikon dan karakter Kabupaten Sumenep yang dikenal masyarakat dengan baik. Dari data primer tersebut kemudian akan digali dan diujikan kepada sejumlah responden di Kabupaten Sumenep tentang identitas kabupaten.

c. Analisis Data Ikon dan Karakter Khas Kabupaten Sumenep

Analisis dilakukan dengan uji ikon dan karakter khas Kabupaten Sumenep kepada sejumlah responden melalui kuisioner. Hasil pengolahan data dan analisis kuisioner kemudian digunakan sebagai objek yang akan dikembangkan mewakili ciri khas Kabupaten Sumenep pada cinderamata untuk tamu Bupati Sumenep.

d. Eksplorasi Pengetahuan Ilmu Kayu Ukir Eksplorasi pengetahun kayu ukir melalui kuliah tamu dari praktisi industri kayu ukir dan studi lapangan ke industri kayu ukir (Jepara dan Bali).

\section{Tahap Perancangan (design)}

Kegiatan pada tahap ini adalah merancang mengembangkan dari data analisa ikon dan karakter Kabupaten Sumenep yang diperoleh. Hasil karya tahap ini adalah berupa konsep desain dan sketsa rancangan desain cinderamata aksesoris interior yang berkarakter khas Kabupaten Sumenep. Produk cenderamata berbahan kayu ukir yang didesain terdiri dari 3 seri. Masing-masing seri akan diproduksi 3 model/prototipe.

Prinsip-prinsip desain cinderamata aksesoris interior berbahan kayu ukir ini adalah :

1) Original

2) Simple

3) Functional

4) Strong

5) Safe

6) Pretty, Funny, Elegant

7) Modern, historical

8) Geometry

Terdapat 30 sketsa desain cinderamata aksesoris interior yang kemudian dianalisa dan dievaluasi untuk kemudian dipilih 3 desain. Desain yang terpilih kemudian dikembangkan berdasarkan serinya dan dibuat prototipe masing-masing.

\section{Tahap Pengembangan (development)}

Proses produksi prototipe cinderemata dilakukan di bengkel kayu ukir Karduluk, Sumenep yang merupakan satu-satunya sentra industri kayu ukir di Madura. Proses produksi dilakukan tetap dipandu oleh desainer.

\section{Tahap Penyebaran (disseminate)}

Tahap ini adalah pemilihan hasil prototipe cinderamata oleh pemerintah Kabupaten Sumenep yang diwakili oleh Bupati Sumenep. Dari 10 prototipe masing-masing seri desain cinderamata kayu ukir dipilih 3 buah untuk kemudian diproduksi lebih banyak lagi oleh Pemerintah Kabupaten Sumenep.

\section{HASIL DAN PEMBAHASAN}

Sentra kerajinan kayu ukir Sumenep produksi desa Karduluk terletak di kecamatan Pragaan, Kabupaten Sumenep, Madura. Meskipun dikenal dengan desa Karduluk namun pada papan nama desa tertulis Sekar Duluk yang artinya 'bunga subur'. Sementara menurut seorang nara sumber, Bapak Badri mengatakan kata Sekar memiliki arti 'gambar', dengan 
kata lain desa Karduluk memiliki banyak sekali seniman (Firdausi, 2012). Secara geografis desa Karduluk berada di wilayah perbukitan, banyak warganya lebih memilih bekerja sebagai tukang mebel dibanding sebagai nelayan. Kondisi cuaca di desa Karduluk juga termasuk stabil, hampir tidak mengenal musim paceklik. Warga berproduksi mebel ukir setiap hari kecuali saat panen tembakau. Produk dipasarkan terbatas warga Madura saja karena preferensi nilai estetika mereka. Diharapkan dengan dilakukannya peneltian dan pengembangan lebih dalam pada potensi desa kerajinan kayu ukir Karduluk, baik dari aspek teknologi, bahan, maupun estetika (trend pasar global), maka potensi yang dimiliki desa Karduluk dapat dioptimalkan.

Luaran penelitian pengembangan desain cinderamata aksesoris interior berbahan kayu ukir yang memiliki ciri khas Sumenep untuk tamu pemerintah Kabupaten Sumenep berupa:

a. Jurnal ilmiah

b. Produk : 30 sketsa desain cinderamata dan 10 prototipe

\section{Pengembangan Produk Terpilih 1:}

Pengembangan produk pertama berupa pembatas buku terbuat dari ukiran dan pahatan kayu dan diselesaikan dengan pewarnaan cat kayu (gambar 1), mengambil inspirasi dari bentuk Gerbang Keraton Sumenep, Labang Mesem (gambar 2). Wujud Labang Mesem dibelah sedemikian rupa menjadikan kedua sisi sebagai pembatas atau penahan buku di atas meja.

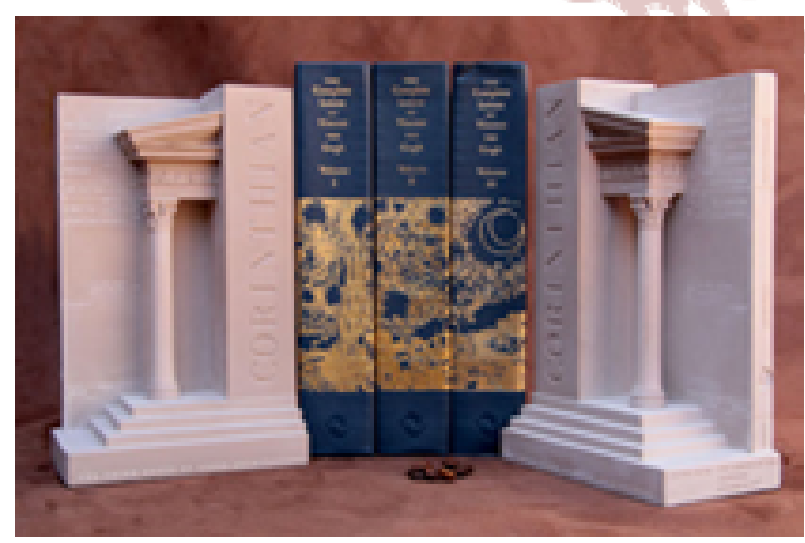

Gambar 1: pembatas buku (sumber: www.google.com/ book partition)

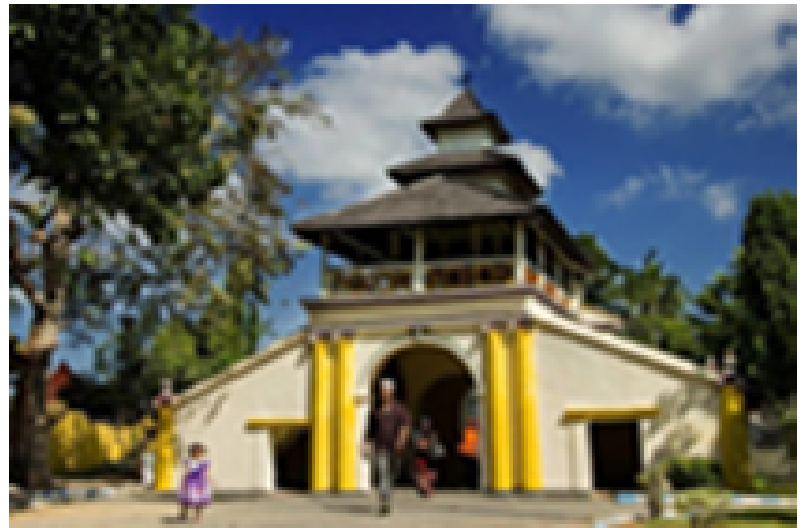

Gambar 2: Gerbang Keraton Sumenep Labang Mesem (sumber: www.google.com/ labang mesem)

\section{Pengembangan Produk Terpilih 2:}

Pengembangan produk ke dua berupa kotak wadah multifungsi, terbuat dari kayu, dengan penyelesaian teknik ukir dan pewarnaan cat kayu alami (gambar 3), mengambil inspirasi dari bentuk sayap kereta milik pemerintahan Kabupaten Sumenep (gambar 4). Gagasan pembuatan kereta oleh KaDisParBud Sumenep, Bapak Sofiyanto, digunakan pada pawai hari jadi Kabupaten Sumenep (nara sumber: Penulis dan Budayawan Sumenep, Bapak Tadjul Arifin).

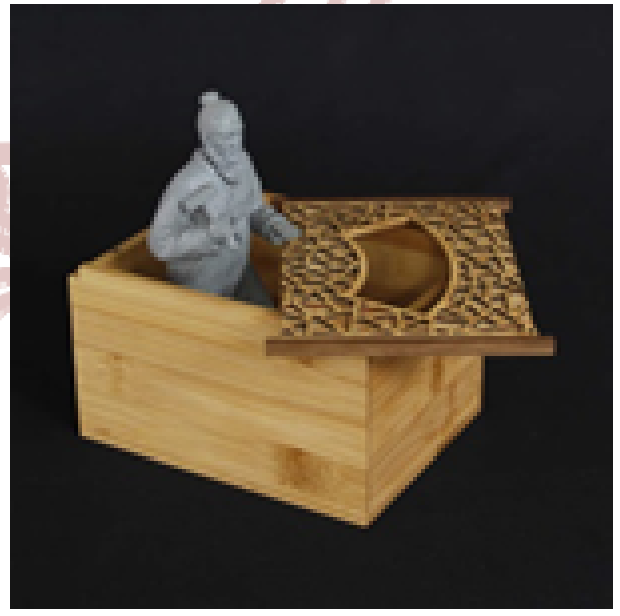

Gambar 3: kotak multifungsi

(sumber: www.google.com/ Modern-Style-BambooTissue-Box-Creative-Eco-Natural-Wood-Seat-TypeTissue-Canister-Home-Table-Decor) 


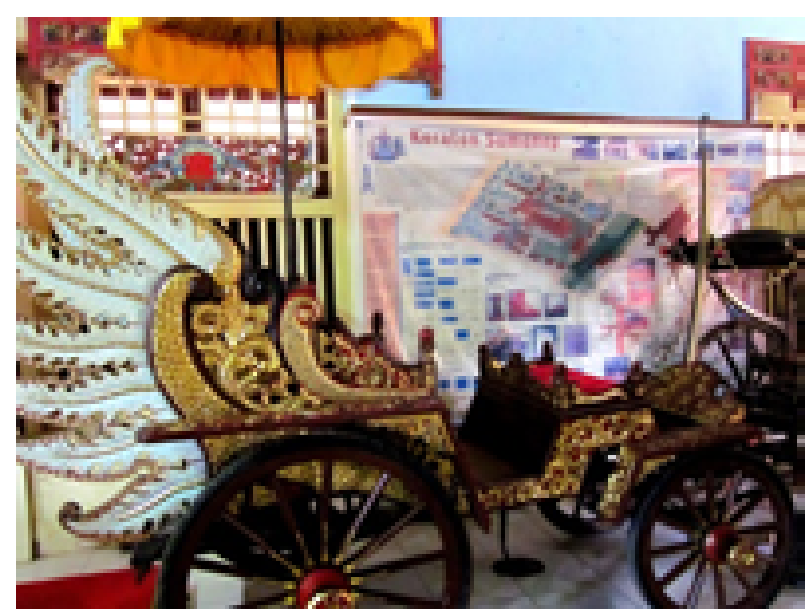

Gambar 4: kereta pawai Kabupaten Sumenep (sumber: www.google.com/ keraton sumenep/ kereta).

\section{Pengembangan Produk Terpilih 3:}

Pengembangan produk ke tiga berupa jam dinding terbuat dari kayu dengan teknik ukir halus dan pewarnaan cat kayu alami (gambar 5), mengambil inspirasi dari ornamen kayu pada bagian atas pintu utama gedung Konign, Keraton Sumenep (gambar 6). Arti atau makna dari ukiran tersebut adalah bahwa seorang penguasa harus mencintai lingkungan dan menampung segala keluhan masyarakat terutama tentang lingkungan hidup. Warna merah dan kuning emas memiliki falsafah kapodhang nyocco sare atau burung kepodang mematuk bunga (rato prappa'na bunga = raja sedang senang).

(nara sumber: Penulis dan Budayawan Sumenep, Bapak Tadjul Arifin).

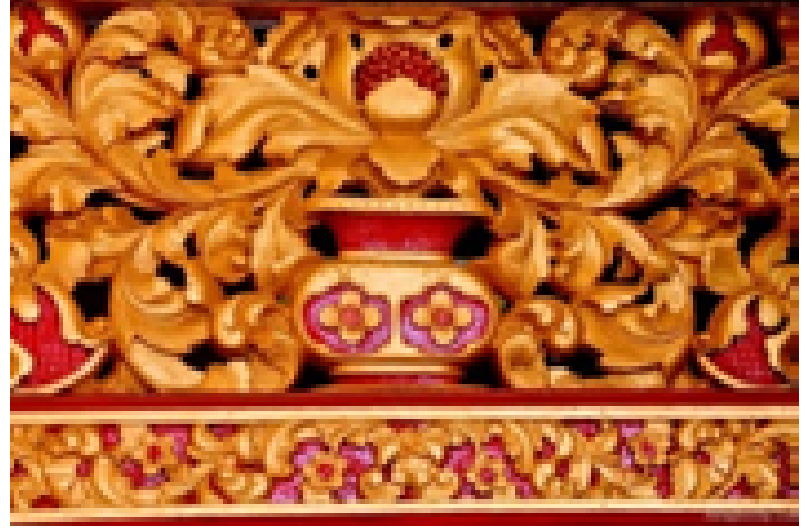

Gambar 6: ornamen kayu gedung Konign, keraton Sumenep

(sumber: www.google.com/Keraton Sumenep/ ukiran).

\section{KESIMPULAN}

Pesona Keraton Sumenep merupakan sumber inspirasi yang tak terbatas untuk pengembangan produk souvenir Kabupaten Sumenep. Potensi yang dimiliki sentra kerajinan kayu ukir Karduluk perlu ditingkatkan secara maksimal oleh berbagai pihak, demi kemajuan industri pariwisata di daerah tersebut. Pengembangan desain souvenir Sumenep dari sentra industri kayu ukir Karduluk adalah solusi optimal untuk pengembangan industri pariwisata setempat.

\section{DAFTAR PUSTAKA}

Fadallah, Ali Akbar, Nia Kurniasih Pontoh. 2014.

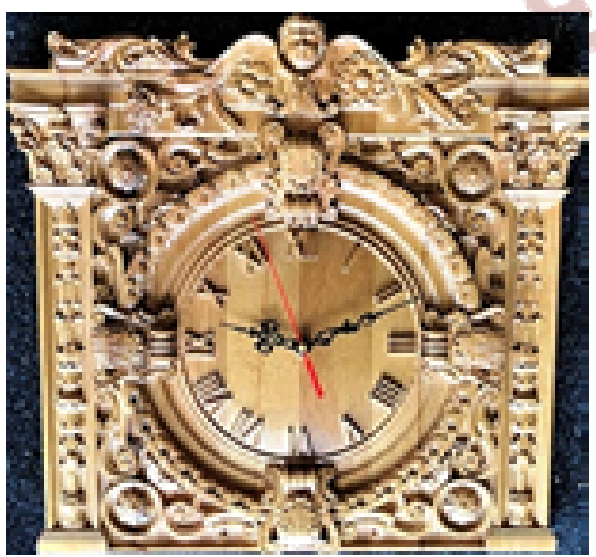

Gambar 5: jam dinding berbahan kayu (sumber: www.google.com/ oak - wooden wall-clock). Jurnal Perencanaan Wilayah dan Kota.

\section{Penerapan City Branding di Indonesia: Studi
Kasus Kota Pekalongan, Jawa Tengah. \\ Penerapan City Branding di Indonesia: Studi
Kasus Kota Pekalongan, Jawa Tengah.}

Firdausi, Ayu, 2012. Karakter Visual Desain Kursi Madura dalam Kaitan dengan Perekmbangan Pemasaran di Indonesia, Tesis, FSRD-ITB.

Mulyana, Agus Rahmat, M. Djalu Djatmiko, Ramlan. 2013. Perancangan Maskot sebagai Cinderamata dalam Upaya "Branding" Itenas.

Orie, R.P. Angger, Poerwadi. 1980. Ukiran Kayu Tradisional Madura, Asal Mula Perkembangannya dan Kemungkinannya di Masa Depan. Fakultas Arsitektur ITS, Surabaya. 